\title{
Романова E.A. \\ Психосоматический симптом как способ выражения и осмысления внутреннего конфликта
}

(Россия, Владивосток)

doi: 10.18411/trnio-12-2021-139

\section{Аннотация}

Обращаясь к теме психосоматического симптома, автор вводит нас в пространство консультирования и психотерапии. С целью определения преимуществ, получаемых клиенткой от существования своей проблемы, он предлагает к использованию технику «Мой симптом». Рефлексии подлежат разные уровни - от воспоминания о первом появлении симптома через установление идентичности до завершающего обсуждения смысла симптома.

Ключевые слова: психосоматический симптом, невротический конфликт, первичная, вторичная, третичная выгоды, смыслообразование.

\section{Abstract}

Turning to the topic of psychosomatic symptom, the author introduces us to the space of counseling and psychotherapy. In order to determine the benefits that the client receives from the existence of her problem, he suggests using the «My Symptom» technique. Reflection is subject to different levels - from the memory of the first appearance of the symptom through the establishment of identity to the final discussion of the meaning of the symptom.

Keywords: psychosomatic symptom, neurotic conflict, primary, secondary, tertiary benefits, meaning formation.

В предложенном фрагменте психотерапии обсуждение выстроено вокруг психосоматического симптома - соматического симптома, ставшего таковым под влиянием психологического фактора [1].

Клиентка А., 59 лет, преподаватель.

Описание процесса консультации

Предлагаем клиентке ответить на вопросы, относящиеся к уровням пирамиды «Я и мой симптом» [2].

Уровень 1. Окружение

Психолог (П). Попробуем разобраться в Вашем отношении к симптому. Где, когда, с кем связано его появление?

Клиентка (K). Появлению симптома (тиннитус) предшествовало переутомление, связанное с работой. Потом мне трижды предлагали - всякий раз предложение звучало как приказ - повышение в должности (место администратора), от которого я, ссылаясь на состояние здоровья, отказывалась. Возникла конфликтная ситуация, последовали «репрессии» - непрофильные курсы, сокращение доли ставки, интриги, - после чего я ещё более ощутила телесное и психическое истощение, тогда же впервые появился шум в ушах. Позже ситуация понемногу выправилась, но внутреннее напряжение, желание отгородиться от подобных напастей остались, как и остался сам симптом. Добавлю, работу свою я люблю, отношу себя к числу лучших сотрудников, так сказать, состою в первых рядах (наследие матери - имею в виду её указания, определившие мои жизненные ценности).

П. Как Вы думаете, какое место занимает симптом в Вашей жизни?

$K$. Этот симптом, которому уже больше полугода, будто не оставил мне места ни для чего другого. Для меня это наиболее сложный недуг, который я когда-либо переносила, он изменил качество моей жизни.

Уровень 2. Поведение

П. Что Вы делаете по отношению к симптому (бей, беги, замри)? 
К. Замри.

П. Что симптом мешает Вам делать?

$K$. Он мешает мне переутомляться, тревожиться, расстраиваться (по поводу унижений и оскорблений), одним словом, не беречь себя. В противном случае этот и без того непрерывный и монотонный звук становится ещё более интенсивным - этого я опасаюсь, как и того, что он не прекратится никогда.

Уровень 3. Способности

П. Симптом способен действовать как враг, друг, наказание? Какую Вашу потребность он способен удовлетворить? Как он влияет на Ваши способности?

$K$. Он не враг - с его приходом я волей-неволей оставила место и силы только для главного. Он где-то друг - помогает собрать это главное, а где-то и не друг - такое обременение. Он где-то наказание - всё решала жить в большей гармонии с собой, да всё откладывала, а где-то и не наказание - таким мучительным способом, но всё же научает меня исполнять свою нужду в жизни, задуманной как-то иначе, которую будет определять не только работа, но и области, доныне нетронутые и ожидающие участия, - тело, душа, вера, доверие. Сейчас я не способна справиться с симптомом, он сильнее меня. Не утрачиваю надежду, что он оставит меня.

Уровень 4. Цели

П. Для чего Вам дан симптом? Какова его цель?

$K$. По-видимому, осознать, что важно сосредоточиться на себе и в то же время обернуться на мир. Не на мир, вызывающий тревогу, а на мир другой, не ограниченный только тревогой.

П. Лучше - болеть или не болеть?

К. Не болеть.

Уровень 5. Убеждения

П. По каким правилам, касающимся здоровья, Вы живёте?

$K$. Ем в меру, не пью-не курю, живу в чистоте, соблюдаю режим сна и т. д. Но много работаю, устаю, не хватает движения, воздуха...

П. Для чего (хорошего/плохого) дан симптом? Он дан для страдания, для защиты, для чего?

К. Думаю, и для того, и для другого. Он дан и для защиты (защищает меня от избытка работы, негативных эмоций), и для страдания (для меня он проблема), но, пожалуй, главное - он дан для изменения (изменяет многое во мне).

Уровень 6. Ценности

П. Ради чего терпите симптом? Для чего симптом так действует? В чём ценность симптома (первичная, вторичная, третичная выгоды)?

$K$. Первичная выгода - через симптом я освобождаюсь от избыточной рабочей нагрузки, дополнительных обязанностей, ответственности - всего того, что принесло бы вступление в новую должность. Тем самым я получаю возможность более сохранять себя, принадлежать себе, реализовывать какую-то иную, более гармоничную, жизнь, которую будет определять не только работа. Вторичная выгода - муж стал относиться ко мне ещё более внимательно и щадяще. Положительные же результаты от существования проблемы в том, что симптом изменяет меня: убирает из моей жизни это «слишком» - слишком уставшая, слишком тревожная, слишком расстраивающаяся; слишком «в работе», «в заботе», «в страдании». Третичной выгоды, полагаю, я не имею, поскольку никаких материальных дивидендов от своей проблемы не получаю.

Уровень 7. Идентичность (Кто Я?)

П. Кто в Ваших отношениях с симптомом Вы, а кто Он? Подберите старую и новую метафору симптома.

$K$. Раньше он был властелином, я его пленницей, или он был царём, я его подданной. Сейчас он - учитель, я - ученица.

Уровень 8. Миссия 
П. Постарайтесь ответить на вопросы «Зачем я миру? Что я даю миру? Каково предназначение симптома?»

К. Я нужна миру, я даю ему, вероятно, что-то важное (мне говорили об этом). Я даю это важное для других, но не всегда для себя. Предназначение симптома - научить меня не только отдавать миру, но и отдавать себе или брать себе (в профессии, в отношении с детьми); не только брать себе, но и отдавать ему (в отношении с супругом).

П. Как Вы думаете, что скрывается за симптомом?

$K$. Разрыв между реальным и желаемым, который не удавалось сократить.

Уровень 9. Смысл (Катамнез)

П. Что Вам даёт мир? В чём смысл симптома?

$K$. Поправить ситуацию жизни - в отношении работы, семьи.

П. Как Вы себя чувствуете?

$K$. Мне нерадостно и негрустно. Я серьёзна, сосредоточена.

П. Предлагаю придумать и описать образ своего актуального состояния.

$K$. Образ, простите, роженицы (боль, страх, надежда на благополучный исход) или образ настольной лампы, тёплой, дающей свет в доме и видимой за его пределами.

\section{Общие выводы}

Психосоматический симптом есть следствие внутреннего конфликта [1]. В случае с клиенткой А. мы констатируем несоответствие между завышенными требованиями к себе (отнесение себя «к числу лучших сотрудников», нахождение «в первых рядах») и ограниченными возможностями («телесное и психическое истощение»), что позволяет квалифицировать конфликт как адаптационный (неврастенический) конфликт по типу «Надо - Могу» [2]. Трудоголизм и перфекционизм, поддерживая невротические потребности в честолюбии и безупречности, оборачиваются истощением ресурсов нервной системы (отметим, в анамнезе женщины - присутствие фигуры властной матери с её вышеназванными директивами). Невротическое расстройство усугубляет психотравма, связанная с конфликтной ситуацией на работе и приведшая к эмоциональному напряжению и прогрессирующему обособлению.

Анализ проведённой терапии позволяет заключить, что симптом в определённой степени выгоден клиентке, поскольку он предоставляет ей следующие преимущества:

- освободить себя от необходимости вступления в должность, связанную с избыточными обязанностями и ответственностью, - симптом выступает дополнительным аргументом для отказа;

- избегнуть негативных эмоций, как-то: чувство оскорбления, страх неудачи, тревога, вина и др.;

- получить дополнительное внимание от мужа.

Одновременно анализ терапии позволяет говорить о том, что симптом в определённой степени изелесообразен, имеет свои положительные результаты, поскольку предоставляет клиентке возможности:

- ограничить удовлетворение невротических потребностей в честолюбии и безупречности;

- вымерить «разрыв между реальным и желаемым»;

- исполнить замысел «жизни, задуманной как-то иначе»: при сохранности главного интереса - работа - возродить области, такие как «тело, душа, вера и доверие».

Итак, наличие симптома помогает клиентке осознать свои цели, ценности и смыслы.

В заключение приведём положение, имеющее методологический характер. Реальной истории жизни как таковой (в смысле готовой и неизменной данности) не существует. На неё можно лишь указать как на то, что рекурсивно открывается и дискурсивно артикулируется в символическом измерении [3]. Дискурс - речь, связующая жизненный опыт в некую целостность, и рекурс - возврат к истокам этого опыта оформляют 
смыслообразование. В случае с клиенткой А. в процессе реконструкции индивидуального опыта, связанного с действием симптома, выявляется то, что не было признано и отсрочено.

\section{План терапевтической работы}

В дальнейшем рекомендуется:

1. продолжить анализ «драйверного поведения», основанного на принятии или отказе от внешних предписаний (установок, аттитюдов), исходящих от значимых фигур;

2. провести работу по отказу от перфекционизма как причины неврастении (техники «Избавление от тирании долженствования», «Колесо жизненного баланса»);

3. провести работу по исследованию актуальных и вытесненных эмоций и пониманию причин возникновения психосоматического симптома (техника «Кувшин эмоций и чувств»);

4. продолжить коррекцию психосоматического симптома с помощью метафорических ассоциативных карт (МАК) (техники «Я и моя болезнь» (В. Голобородова), «Хозяин симптома» (В. Шебанова).

$$
* * *
$$

1. Величко, М. Психосоматика / М. Величко. - М.: Издательский дом «Кислород», 2020. - 304 с.

2. Дмитриева, Н.В. Неврозы и невротики. Глубинная терапия с помощью ассоциативных карт / Н.В. Дмитриева, И.С. Богачек. - СПб.: ВВМ, 2019. - 229 с.

3. Сакутина, Т.М. История жизни: метапсихологический план исследования / Т.М. Сакутина // Рекурсивное и дискурсивное в структуре смыслообразования /Под ред. В.А. Сакутина. - М.: Смысл, 2004. - С. 90-110.

\section{Самотолкова Ю.С., Ушатова Т.Е.}

Настольная игра в работе психолога как способ адаптации ребенка в 1 классе

МКУ ДО «Районный ичентр диагностики и консультирования для детей, нуждающихся в психолого-педагогической, медицинской и соџиальной помощи» (Россия, Козельск)

doi: 10.18411/trnio-12-2021-140

\section{Аннотация}

Данная работа описывает роль игровой деятельности, а в частности роль настольной игры в адаптации первоклассника. Представлены результаты апробации созданной игры специалистами МКУ ДО РЦДиК г.Козельск «Школьный Rule Time». Описаны плюсы индивидуальной и групповой форм игры, а также приведены общие плюсы использования данного методического материала.

Ключевые слова: игра при адаптации школьника, настольная игра в работе с первоклассником, ведущий вид деятельности, групповая игра, индивидуальная игра.

\section{Abstract}

This work describes the role of gaming activity, and in particular the role of a board game in the adaptation of a first-grader. The results of the testing of the created game by the specialists of the MCU BEFORE the RCDiK are presented .Kozelsk "School Rule Time". The advantages of individual and group forms of play are described, as well as the general advantages of using this methodological material.

Keywords: a game in the adaptation of a student, a board game in working with a first-grader, a leading type of activity, a group game, an individual game. 